\title{
Restricting quantifier scope in Dutch: Evidence from child language comprehension and production
}

\author{
Petra Hendriks, Ruth Koops van 't Jagt \& John Hoeks
}

\begin{abstract}
In this study, we tested 4- to 6-year-old Dutch children and adults on their comprehension and production of indefinite subjects and objects in universally quantified sentences. Our comprehension results show that, whereas the adults showed a strong preference for indefinite subjects to refer to specific entities, corresponding to a wide scope interpretation for the indefinite subject, the children overwhelmingly accepted non-specific referents for indefinite subjects, corresponding to a narrow scope interpretation. In the production task, however, the children, like the adults, did not use indefinite subjects to express non-specific reference. Although this seems to indicate that children's non-adult-like performance with indefinite subjects is limited to comprehension, their pattern of production was slightly different from that of adults, too. We suggest that this may be due to a non-adult-like ranking of constraints on specificity and familiarity.
\end{abstract}

\section{Introduction}

In English, transitive sentences with an indefinite subject and a universally quantified direct object such as (1) are generally ambiguous and can refer to a situation in which there is a specific bear who tickles all the turtles, as well as to a situation in which each turtle is tickled by a different bear.

(1) A bear tickles every turtle.

These two interpretational possibilities are usually semantically distinguished in terms of quantifier scope: In the former case, the indefinite has wide scope over the universal quantifier, and in the latter case, the indefinite has narrow scope with respect to the universal quantifier. Similar sentences in Dutch, however, strongly resist the narrow scope reading for the indefinite subject. Surprisingly, in contrast to Dutch adults, 
Dutch children seem to behave like English adults and allow the narrow scope reading until quite a late age (Philip, 2005).

The difference between Dutch adults and Dutch children can be explained in a number of different ways. First, it is conceivable that the dispreference for the narrow scope reading in adult Dutch is caused by some syntactic property of Dutch that children have not yet mastered. If this explanation is correct, we expect the same Dutch children to make corresponding errors in their production. On the other hand, the dispreference for a narrow scope reading for indefinite subjects in Dutch may also be the result of a pragmatic restriction on the interpretation of indefinite subjects in Dutch. This explanation allows for the possibility that Dutch children's production of quantifier scope is perfectly adult-like. A third possibility is that the preference for a wide scope reading is caused by a semantic property of indefinites such as specificity, which could influence adults' and children's production of indefinites differently.

The aim of this paper is to shed more light on the lack of quantifier scope ambiguities with indefinite subjects and universally quantified objects in adult Dutch, and its presence in child language, by studying comprehension as well as production of such sentences. This paper is organised as follows. Section 2 discusses the three explanations for the dispreference for the narrow scope reading in adult Dutch mentioned above in more detail. These explanations differ in the predictions they make about children's production. Section 3 describes our study, which tests comprehension as well as production of universally quantified sentences in children and adult controls. The results of the comprehension task are presented and discussed in section 4, and the results of the production task are presented and discussed in section 5 . As we will show, considering comprehension as well as production of the same linguistic form can help to decide among competing linguistic explanations.

\section{Quantifier scope in Dutch}

Why are Dutch indefinites restricted in their scopal possibilities? In section 2.1, we discuss three possible explanations: a syntactic explanation, a pragmatic explanation and a semantic explanation. Section 2.2 shows how these explanations can account for children's non-adult pattern of interpretation, and section 2.3 discusses their predictions with respect to production. 

comprehension and production 3

\subsection{Restricting quantifier scope}

A first explanation for the restricted scopal possibilities of indefinites in Dutch is suggested by Beghelli and Stowell (1997) in their article on English every and each. In this article, they propose a syntactic account of quantifier scope, according to which scopal ambiguity arises because various landing sites are available to indefinites for covert movement. Depending on the landing site, the indefinite takes wide or narrow scope with respect to a quantifier or negation. Discussing cross-linguistic evidence for their syntactic account of quantifier scope, Beghelli and Stowell point out that in various Germanic languages, such as Dutch, specific readings of scrambled indefinite objects are necessarily associated with overt leftward movement out of the VP.

With respect to the interpretation of scrambled indefinite objects, Dutch children were found to differ from Dutch adults: They do not distinguish between indefinite objects in unscrambled position and indefinite objects that have scrambled out of the VP to a position to the left of a sentential adverbial like negation, and preferably assign a non-specific interpretation to indefinite objects in both positions (Krämer, 1998; Unsworth, 2007). Although Beghelli and Stowell do not discuss indefinite subjects in Germanic languages, it is conceivable that the specific reading of indefinite subjects in Dutch is also associated with a particular scope position to which the indefinite subject moves. Consequently, children's non-adult comprehension of indefinite objects in scrambled position and indefinite subjects in sentence-initial position may receive a similar explanation in terms of difficulty with leftward movement or the absence of an appropriate landing site. This syntactic account would thus predict that children's non-adult pattern in comprehension may be accompanied by word order errors in production. That is, children who assign a nonspecific interpretation to scrambled indefinite objects are predicted to have problems with overt leftward movement of indefinite objects. Similarly, children who assign a non-specific interpretation to indefinite subjects in sentence-initial position may experience problems with leftward movement of indefinite subjects. This should then result in errors with verb second in Dutch, which not only requires the finite verb in main clauses to move from sentence-final position to the second position but, in canonical sentences, also requires the subject to move to a position in front of the verb. Children's errors with verb second typically consist in leaving the verb (usually in the infinitive form) in sentence-final position or in using 
verb-subject order (Wijnen \& Verrips, 1998). Thus, if children's acceptance of the narrow scope reading of indefinite subjects is caused by their inability to move the indefinite subject to an appropriate landing site to the left of the verb, we expect these children to produce ungrammatical sentences in which the verb is left in final position or which have verbsubject order.

An alternative explanation for the dispreference for the narrow scope reading in adult Dutch is Philip's (2005) pragmatic account. Philip argues that the interpretation of indefinite subjects in Dutch is restricted by a construction-specific and language-specific pragmatic rule. For Dutch transitive sentences with a sentence-initial subject and a universally quantified direct object, this rule requires listeners to select the strongest possible meaning consistent with the context of use, in accordance with the Strongest Meaning Hypothesis (Dalrymple et al., 1994). Because the wide scope interpretation implies the narrow scope interpretation but not vice versa (if a specific bear tickles all the turtles, then it is also true that each turtle is tickled by some bear, but not the other way around), the wide scope interpretation is the strongest of the two. If both interpretations are possible, Philip argues, Dutch adults will choose the wide scope interpretation.

The pragmatic nature of the rule would explain why the rule is not yet available to Dutch children from an early age on: as the rule is not innately specified, it must be learned from the language input, which is expected to take time. Also, its pragmatic nature would explain why there is considerable variation across adult native speakers of Dutch. According to Philip, for many speakers of Dutch "it is always in principle possible for a high indefinite subject to be nonspecific as long as the verb is transitive" (2005: 274). Because Philip's rule is an 'interpretive rule' that selects a particular interpretation under specific structural conditions, it only applies in interpretation. Therefore, if no additional assumptions are made, Philip's construction-specific interpretive rule will predict a delay in Dutch children's comprehension of indefinite subjects while at the same time predicting adult-like production of these forms.

A third explanation for the lack of the narrow scope reading in adult Dutch, is that indefinite subjects in canonical position in Dutch must receive a specific interpretation for independent reasons. Because a specific interpretation is incompatible with a narrow scope reading of the indefinite, the narrow scope reading is blocked. De Hoop and Krämer $(2005 / 6)$ offer such a semantic explanation in terms of Optimality Theory (OT; Prince \& Smolensky, 1993/2004). According to their OT account of 


\section{Restricting quantifier scope in Dutch: Evidence from child language comprehension and production 5}

indefinites in Dutch, indefinite subjects in canonical sentence-initial position must receive a specific (or, in their terminology, referential) interpretation, and indefinite objects in canonical non-scrambled position must receive a non-specific interpretation, as a result of the interaction between two constraints of the grammar:

Constraints on specificity (adapted from de Hoop and Krämer, 2005/6):

M1: Subjects get a specific interpretation; objects get a non-specific interpretation.

M2: Indefinite noun phrases get a non-specific interpretation.

These two constraints are in conflict when interpreting an indefinite subject, as satisfaction of M1 requires that the indefinite subject receives a specific interpretation whereas satisfaction of $\mathrm{M} 2$ requires that the indefinite subject receives a non-specific interpretation. However, if M1 is stronger than M2 (as de Hoop and Krämer argue to be the case for Dutch adults), satisfaction of M1 is more important than satisfaction of M2 and hence indefinite subjects of Dutch transitive sentences receive a specific interpretation. For indefinite objects, the two constraints are not in conflict and each promote a non-specific interpretation.

\subsection{Acquiring quantifier scope}

As mentioned above, the syntactic explanation suggests that Dutch children interpret indefinite subjects non-specifically because they fail to move indefinite subjects into the relevant scope position. According to the pragmatic explanation, Dutch children do not yet know the languagespecific pragmatic rule and hence allow an indefinite subject to receive a weak, non-specific, interpretation. So how does the semantic explanation account for Dutch children's interpretation of indefinite subjects in universally quantified sentences?

De Hoop and Krämer (2005/6) show how the constraints M1 and M2 account for children's non-adult-like interpretations of indefinites in special, marked, positions, such as the sentence-internal position of the subject in existential there-constructions and the scrambled position of the object to the left of a sentential adverbial. Because children have a general preference for subjects to be specific and objects to be non-specific, which is reflected by M1, they incorrectly interpret indefinite subjects in existential constructions as specific, too. Similarly, they incorrectly 
interpret indefinite objects in scrambled position as non-specific. Adults distinguish between subjects and objects in canonical position and in marked position, de Hoop and Krämer argue, because they take into account the perspective of the speaker. For reasons of economy, speakers prefer subjects and objects in their canonical position over subjects or objects in marked position. If listeners take into account the speaker's choices and reason that the speaker would have used an unmarked form to express an unmarked interpretation, by this reasoning marked forms such as indefinite subjects in existential constructions and indefinite objects in scrambled position receive a marked interpretation. That is, indefinite subjects of there-sentences receive a non-specific interpretation, and scrambled indefinite objects receive a specific interpretation. As de Hoop and Krämer claim, children until the age of 7 or perhaps even later still lack the ability to take into account the speaker's perspective when interpreting these marked forms. Hence, they assign an unmarked interpretation to unmarked as well as marked forms.

If children fail to take into account the speaker's perspective but already know that M1 must be given more weight than M2, as de Hoop and Krämer claim, they are predicted to interpret indefinite subjects in their canonical sentence-initial position as specific, just like adults do. To support the validity of this claim, de Hoop and Krämer refer to an empirical study by Bergsma-Klein (1996), who concludes that 4- to 8-year old Dutch children correctly assign a specific reading to indefinite subjects of intransitive sentences. However, this is not what Philip (2005) found in his study with 142 Dutch-speaking 6- to 12-year-olds. Philip's 6-year-olds assigned a non-specific interpretation to the indefinite subject een vogel 'a bird' in the transitive test sentence Een vogel heeft elke bosbes opgegeten ('a bird has eaten each blueberry') in $33 \%$ of the cases. Surprisingly, the percentage of non-specific interpretations by children did not decrease with age and was the same in the 12-year-olds tested.

Children's relative lack of specific interpretations remains unexplained if children know that M1 is stronger than M2. However, in Optimality Theory children's non-adult pattern can straightforwardly be explained by their lack of knowledge of the relative weights of the two constraints. In OT, a grammar consists of a set of universal constraints and their ranking. Hence, language variation as well as language acquisition is captured in terms of different rankings of these constraints (Prince \& Smolensky, 1993/2004, 1997; Tesar \& Smolensky, 1998). A different ranking of the same constraints could explain the difference between Dutch and English with respect to the scope of indefinite subjects. In addition, it could 
provide an explanation for the acquisition of indefinite subjects in Dutch. Children may start with a non-adult ranking of the relevant constraints and learn the adult ranking by reranking the constraints on the basis of the language input they receive.

The inverse ranking of $\mathrm{M} 1$ and $\mathrm{M} 2$, with $\mathrm{M} 2$ ranked above $\mathrm{M} 1$, gives rise to the interpretational pattern shown by Dutch children as well as English adults. That is, if M2, which says that indefinite noun phrases get a non-specific interpretation, is the strongest of the two constraints, the OT grammar predicts that all indefinites can receive a non-specific interpretation, even indefinite subjects. As a result, for Dutch children as well as English adults indefinite subjects can be non-specific and hence allow a narrow scope interpretation. So the difference between Dutch adults, on the one hand, and Dutch children and English adults, on the other, could be explained by a different ranking of M1 and M2 in the grammar: Dutch adults rank M1 above M2, and Dutch children and English adults rank M2 above M1.

\subsection{Producing sentences with indefinites}

In OT, comprehension and production are assumed to be mediated by the same grammar, with the same constraints under the same ranking. The effects of these constraints may differ, however, because the nature of input and output to optimization differ: in comprehension, the output is an interpretation, whereas in production, the output is a form. Particular constraints in OT pertain to the output only and hence either apply to interpretations or to forms. Using this property of OT constraints, for example, Hendriks and Spenader (2005/6) explain the remarkable phenomenon that English and Dutch children make errors in their interpretation of object pronouns until the age of 7 (the so-called Delay of Principle B Effect) but show adult-like performance in production from an early age on. To determine the predictions of an OT account of quantifier scope, we have to consider the effects of M1 and M2 as applied to potential output forms for a particular input meaning.

Under either ranking of the constraints $\mathrm{M} 1$ and $\mathrm{M} 2$, a grammar consisting of only these two constraints predicts that if the input is a specific referent, the best form to express that meaning is a definite; a definite satisfies M2, whereas an indefinite would violate this constraint. This is illustrated by the following OT tableau: 


\begin{tabular}{|l||l|l|}
\hline $\begin{array}{l}\text { Input: } \\
+ \text { Spec }\end{array}$ & $\begin{array}{l}\text { M1: } \\
* \text { S/-Spec } * \text { O/+Spec }\end{array}$ & $\begin{array}{l}\text { M2: } \\
* \text { Indef/+Spec }\end{array}$ \\
\hline \hline \multicolumn{1}{|l}{ Indef } & & $* !$ \\
\hline$\varpi$ Def & & \\
\hline
\end{tabular}

Figure 1. OT tableau of adult speakers' choice of form for a specific referent.

In an OT tableau, the constraints are given in the first row, ordered according to strength from left to right. Here, the notation *Indef/+Spec (M2) must be read as: Avoid indefinites that are specific. In the adult grammar, M1 is stronger than M2. The input meaning is given in the lefthand corner. The relevant candidates for expressing the input meaning are listed in the first column below this input. The optimal form is the form that satisfies the constraints of the grammar best because it incurs the least severe constraint violations. Constraint violations incurred by a candidate output are shown in the row of that candidate, and are indicated by an asterisk in the corresponding cell. Because the violation of M2 makes the indefinite less preferred in comparison to the definite, this violation is fatal (marked by $* !$ ) and hence a definite is the optimal form (indicated by ${ }^{*}$ ). Note that the violation of M2 by the indefinite is not fatal in an absolute sense but only in comparison to the constraint violations incurred by the definite: If another but stronger constraint were relevant that would be violated by a definite but not by an indefinite, this violation would be fatal for the definite and consequently the indefinite would be the optimal form, despite its violation of M2.

With respect to the production of non-specific referents, the constraints are indecisive: M1 does not distinguish between indefinite and indefinite subjects and objects, and indefinites and definites both satisfy M2:

\begin{tabular}{|l||l|l|}
\hline Input: & M1: & M2: \\
-Spec & $*$ S/-Spec; $*$ O/+Spec & $*$ Indef/+Spec \\
\hline \hline Indef & & \\
\hline Def & & \\
\hline
\end{tabular}

Figure 2. OT tableau of adult speakers' choice of form for a non-specific referent.

Because the constraint profiles of indefinites and definites are identical for a non-specific input meaning, speakers may select a definite or an 


\section{comprehension and production 9}

Restricting quantifier scope in Dutch: Evidence from child language

indefinite at random, or perhaps base their choice on other factors that we have not considered here, such as givenness. Furthermore, as there is no situation in production where the two constraints are in conflict, both constraint rankings yield the same output. So if the same two constraints M1 and M2 that explain the dispreference for the narrow scope reading in adult Dutch are applied to production, it is predicted that adults and children will show the same pattern. Both groups are predicted to avoid producing the Dutch equivalent of the sentence $A$ bear tickles every turtle when reference is intended to a specific bear. Instead of an indefinite subject, they will use a definite subject. If, on the other hand, reference is intended to a non-specific bear, they are predicted to use either an indefinite or a definite subject. Similar predictions are made for indefinite objects.

Summarizing, the three possible explanations for the restricted scopal possibilities of Dutch discussed in this section make different predictions about children's production of sentences with indefinite subjects. For the semantic explanation, these predictions are independent of the occurrence of a universal quantifier and hold for indefinite subjects in general. The syntactic explanation predicts that children who show a non-adult pattern in comprehension also make word order errors in production. The pragmatic explanation predicts that these children's production will be completely adult-like; however, no predictions are made about the exact pattern of production. The semantic explanation, on the other hand, does make predictions about the exact pattern of production for specific and non-specific referents. First of all, it predicts that children as well as adults will generally avoid using indefinites to refer to specific referents. Furthermore, because children and adults employ a different constraint ranking, it allows for the possibility that in particular situations - governed by additional constraints, which may interact with M2 - children produce non-adult-like forms for specific referents.

\section{Experiment}

To test these predictions and to determine the role of specificity in the comprehension and production of quantifier scope, a group of children and a group of adult participants were tested on both a comprehension task (picture verification) and a production task (elicited production). 


\subsection{Participants}

Participants in the study were 17 Dutch-speaking children (age 4;6 - 6;8, mean age 5;11) and 20 Dutch-speaking adults (age 18;0 - 46;6, mean age $23 ; 7)$. In total, 31 children were tested. However, 14 of these children made more than one error with the 6 control items (see section 3.2 on Materials and design), or did not complete the comprehension task, and were therefore excluded from analysis.

\subsection{Materials and design}

Two types of sentences were used in the comprehension task: sentences with an indefinite in subject position and a universal quantifier in object position (IS-QO), and sentences with a universal quantifier in subject position and an indefinite in object position (QS-IO):

(2) Een beer kietelt elke schildpad. (IS-QO surface order) 'a bear tickles every turtle'

(3) Elke beer kietelt een schildpad. (QS-IO surface order) 'every bear tickles a turtle'

These two sentence types were combined with picture sequences consisting of three pictures each, as shown in Figure 3. Three types of picture sequences were used: with 1 actor and 3 undergoers (sequence 1-3), with 3 actors and 3 undergoers (sequence 3-3) and with 3 actors and 1 undergoer (sequence 3-1). Sentences with an indefinite subject (IS-QO sentences) were presented with picture sequences showing one (1-3) or three (3-3) actors, corresponding to a specific or non-specific interpretation of the indefinite subject, respectively. Similarly, sentences with an indefinite object (QS-IO sentences) were presented with picture sequences with one (3-1) or three (3-3) undergoers, corresponding to a specific or non-specific interpretation of the indefinite object. We thus have four conditions in comprehension. The comprehension task consisted of 16 transitive test items ( 4 per condition), preceded by 2 practice items. In addition to these items, the comprehension task also included 6 intransitive control items ( 3 target 'yes' and 3 target 'no' items, also with sequences of three pictures) with indefinite or universally quantified subjects, such as Elke schildpad slaapt 'every turtle is asleep'. After testing, we removed participants from our analysis who made more than one error with these control items and 

comprehension and production 11

hence did not yet comprehend indefinites or quantifiers correctly, did not properly understand the task, or displayed a yes bias in their responses. Two lists were created of the test items and control items, with a different order of items.

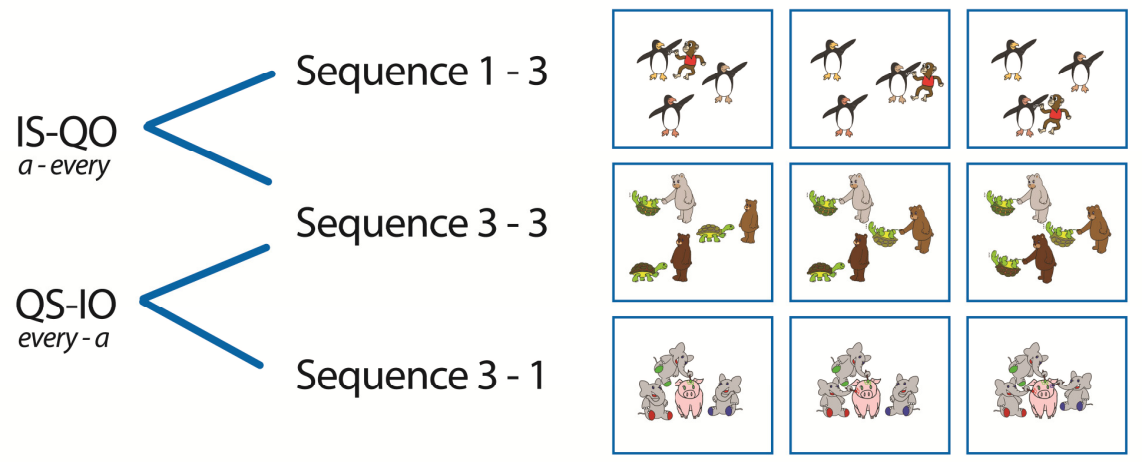

Figure 3. In the comprehension task, two sentence types were combined with two types of picture sequences each. In the production task, the same three types of picture sequences were used as in the comprehension task.

Based on the findings of Philip (2005), we expect children to accept the sentences in all four conditions. Although Philip did not consider the interpretation of indefinite objects, on the basis of the literature on the acquisition of indefinite objects in Dutch we expect the interpretation of indefinite objects to be unproblematic for Dutch children, as indefinite objects in canonical position are preferably interpreted as non-specific by adults as well as children (see de Hoop \& Krämer, 2005/6, for discussion). In contrast to children, we expect adults to reject IS-QO sentences such as (2) for picture sequence 3-3 in the majority of cases, as for these sentences a specific interpretation of the indefinite subject is preferred. In the other three conditions, adults are expected to accept the sentences as correct descriptions of the picture sequences.

In the production task, the same three types of picture sequences were used as in the comprehension task, but with new pictures. The production task consisted of 12 test items ( 4 per condition), preceded by 2 practice items. Again, two lists were created of the test items. Depending on the adopted explanation for children's non-adult pattern in comprehension, children who assign a non-specific interpretation to indefinite subjects are expected (1) to make word order errors in production, (2) to show a completely adult-like pattern in production, or (3) to show a largely adult- 
like pattern in production and prefer definites over indefinites when referring to a specific referent.

\subsection{Procedure}

Participants were tested individually by two experimenters. They all received a comprehension task and a production task, in that order. In the comprehension task, the three pictures of each picture sequence were presented to the participant on a laptop screen one at a time. All sentences were pre-recorded and care was taken that their intonation was as neutral as possible. The pre-recorded sentence was played while the third picture was visible on the screen. Participants were asked to respond by pressing the 'yes' button if the sentence matched the picture sequence, or the 'no' button in case of a mismatch. In the production task, the same three types of picture sequences were presented as in the comprehension task, again one picture at a time. Participants were asked to give a one-sentence description of the third picture. No specific instructions were given regarding the form of the sentence. Only for the children the two tasks involved a puppet, to encourage them to respond. The puppet was said to have messed with the sentences in the comprehension task and to be unable to see the pictures in the production task.

\section{Comprehension}

\subsection{Results}

If indefinite subjects are assigned a specific interpretation, which corresponds to a wide scope reading for the indefinite, participants are expected to reject sentences with an indefinite subject (IS-QO sentences) as an adequate description of a situation with multiple actors (3-3 picture sequences). In contrast, the same sentences should be accepted for a situation with a unique actor (1-3 picture sequences). If indefinite objects do not require a specific interpretation, sentences with an indefinite object (QS-IO sentences) should be accepted as a description of 3-3 picture sequences as well as 3-1 picture sequences.

The results of the comprehension task are shown in Figure 4. 

comprehension and production 13

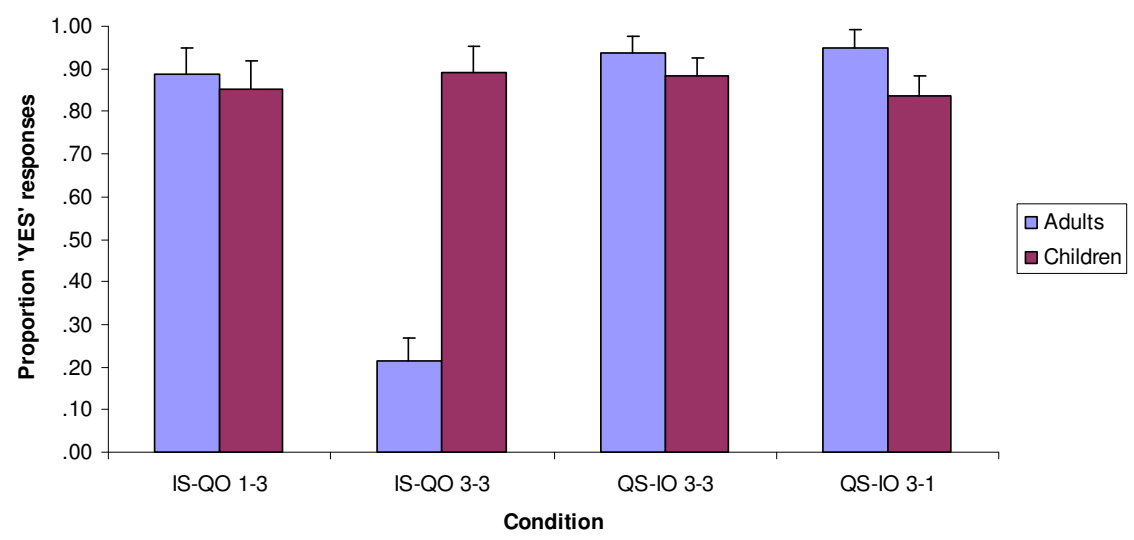

Figure 4. Proportion of 'yes' responses by adults and children in the comprehension task (based on means by participants). IS-QO = sentence with indefinite subject and quantified object; QS-IO = sentence with quantified subject and indefinite object; $1-3=$ picture with one actor and three undergoers; $3-3$ = picture with three actors and three undergoers; 3 $1=$ picture with three actors and one undergoer. Error bars represent one SE.

Proportions correct per participant were arcsine transformed and subjected to a Repeated Measures ANOVA with Group (children vs. adults) as a between-participants factor, and Condition (with levels "IS-QO 1-3", "ISQO 3-3", "QS-IO 3-3" and "QS-IO 3-1") as a within-participants factor. To guard against possible violations of the statistical assumption of sphericity, the Huynh-Feldt correction was used whenever factors with more than two levels were involved (Stevens, 1992). We report the actual degrees of freedom that were used in the statistical test, rounded to the nearest integer. The results showed main effects of both Group $(\mathrm{F}(1,35)=4.1 ; \mathrm{p}=.05)$ and Condition $(\mathrm{F}(3,101)=28.9 ; \mathrm{p}<.001)$. These main effects were qualified by a significant interaction between Group and Condition $(\mathrm{F}(3,101)=36.8$; $\mathrm{p}<.001$ ). Follow-up analyses by means of independent group t-tests for each condition showed a significant difference in 'yes' responses between children and adults in the IS-QO 3-3 condition ( $\mathrm{t}(35)=7.9 ; \mathrm{p}<.001)$, where adults gave substantially fewer 'yes' responses than children (.21 ( $\mathrm{SE}=.06)$ vs. $89(\mathrm{SE}=.06)$ ), and a marginally significant difference in the QS-IO 3-1 condition $\left(\mathrm{t}(26)^{2}=-1.8 ; \mathrm{p}=.081\right)$, where adults tended to give more 'yes' responses than children (.95 ( $\mathrm{SE}=.04)$ vs. $.84(\mathrm{SE}=.05))$. No significant differences emerged in the other two conditions (all p-values $>.40$ ). 


\subsection{Discussion}

The results of the comprehension task reveal that 4- to 6-year-old Dutch children allow indefinite subjects to be interpreted non-specifically. They accepted sentences with an indefinite subject for situations with a nonspecific referent in $89 \%$ of the cases, whereas adults accepted such sentences in only $21 \%$ of the cases. The adult responses indicate that adults have a strong preference to interpret an indefinite subject in sentenceinitial position as referring to a specific individual. ${ }^{3}$ On the other hand, children as well as adults allow a non-specific interpretation for indefinite objects.

Our comprehension results for adults (21\% acceptance) are comparable to Philip's (2005) results (16\% acceptance). However, the children in our study (mean age 5;11) allowed a non-specific reading for indefinite subjects much more often, namely in $89 \%$ of the cases, than the youngest age group in Philip's study (mean age 6;5), who allowed a non-specific reading in only $33 \%$ of the cases. This difference might be due to the fact that we tested slightly younger children than Philip did, which would suggest a steep learning curve around the age of 6. Alternatively, the quantitative difference between the children's responses in the two studies may have been caused by differences between the experimental tasks. Philip used a truth-value judgment task with an elaborate story to introduce the single test sentence Een vogel heeft elke bosbes opgegeten ('a bird has eaten each blueberry'). At the beginning of this story, three birds were introduced: a fat bird, a thin bird and a small bird. Throughout the story, these birds are referred to with definite noun phrases. If children know that indefinites generally introduce new referents in the discourse and do not refer to referents that are already given, they may have rejected the test sentence for the wrong reason. However, there is some doubt as to whether children are actually able to use givenness information appropriately in an experimental setting. ${ }^{4} \mathrm{We}$ will return to the issue of givenness below, as it may also be relevant for our interpretation of the production results. Suffice it to say that in our comprehension task, we did not provide any introductory linguistic discourse but presented the pre-recorded test sentence out of the blue as a description of the picture sequence on the computer screen. Consequently, the indefinite subjects and indefinite objects in our test sentences are felicitous as far as their givenness status is concerned. 

comprehension and production 15

\section{Production}

\subsection{Results}

In the production task, participants were asked to give a one-sentence description of the third picture of the sequence, without being given instructions about the specific form of the sentence. As a consequence, many different forms were produced. We were interested in the participants' production of transitive IS-QO and QS-IO sentences in the active voice, which were the test items in the comprehension task, as well as in their production of other forms to express a specific or non-specific meaning of the subject or object. These latter forms include sentences with definite subjects and objects. We coded as indefinite noun phrases (IS and IO) all singular forms with the indefinite article een, plural forms without an article, and singular and plural forms with bare numerals (één 'one', drie 'three'). We coded as universally quantified expressions (QS and QO) all expressions with one of the quantifiers elke 'every', alle 'all' or iedere 'each' (iedere was used only a few times by children and adults, but elke and alle occurred frequently). Definite noun phrases (see below) included all noun phrases with a definite article (de or het) or a universal quantifier (elke, alle or iedere). The participants' production of IS-QO and QS-IO sentences is shown in Figure 5:

\section{Production}

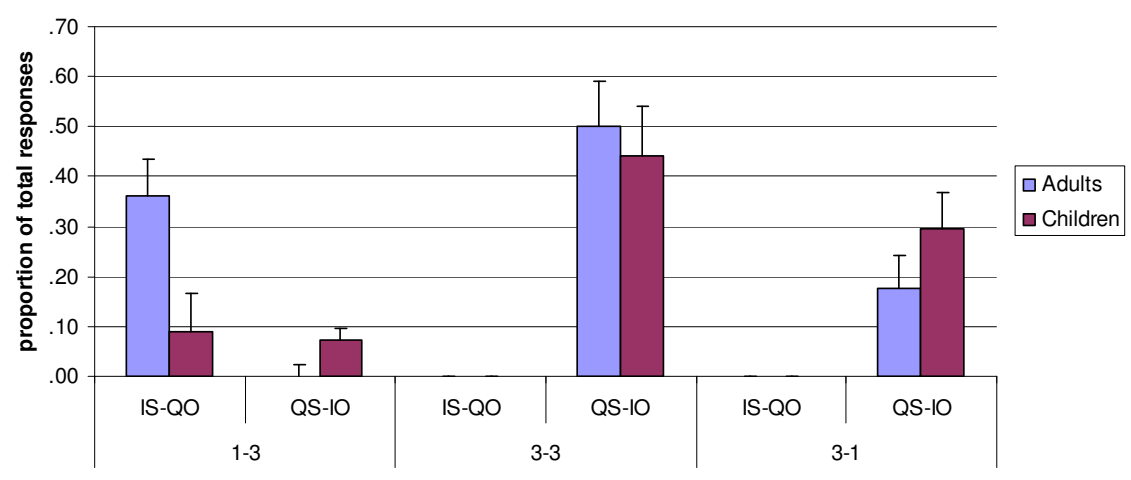

Figure 5. Production of IS-QO and QS-IO utterances in the active voice for the 13, 3-3, and 3-1 picture sequences by adults and children. 
Proportions of IS-QO and QS-IO responses were calculated per participant and then arcsine transformed. Neither children nor adults produced any ISQO utterance in the 3-3 pictures and the 3-1 pictures. Therefore, instead of an ANOVA, we ran an independent groups t-test. We found a significant difference between children and adults in proportions IS-QO in the remaining 1-3 pictures $(\mathrm{t}(30)=-2.7 ; \mathrm{p}<.01)$. The transformed proportions of IS-QO and QS-IO responses were then each entered into a Repeated Measures ANOVA with Group (children vs. adults) as a betweenparticipants factor, and Picture (1-3, 3-3, or 3-1) as a within-participants factor. Huynh-Feldt correction was applied where appropriate; actual degrees of freedom are reported, rounded to the nearest integer. There were no significant differences between the groups as far as the QS-IO responses were concerned: There was no main effect of Group $(\mathrm{F}<1)$, nor was there a significant interaction between Group and Picture (p-value>.24). The main effect of Picture was significant $(\mathrm{F}(2,59)=35.0 ; \mathrm{p}<.001)$, indicating that most QS-IO responses were made to 3-3 pictures (mean=.47; $\mathrm{SE}=.07$ ), followed by 3-1 pictures (mean=.24, $\mathrm{SE}=.05$ ), and fewest to 1-3 pictures (mean=.04, $\mathrm{SE}=.02$ ); all differences between the pictures were significant (p-values<.001).

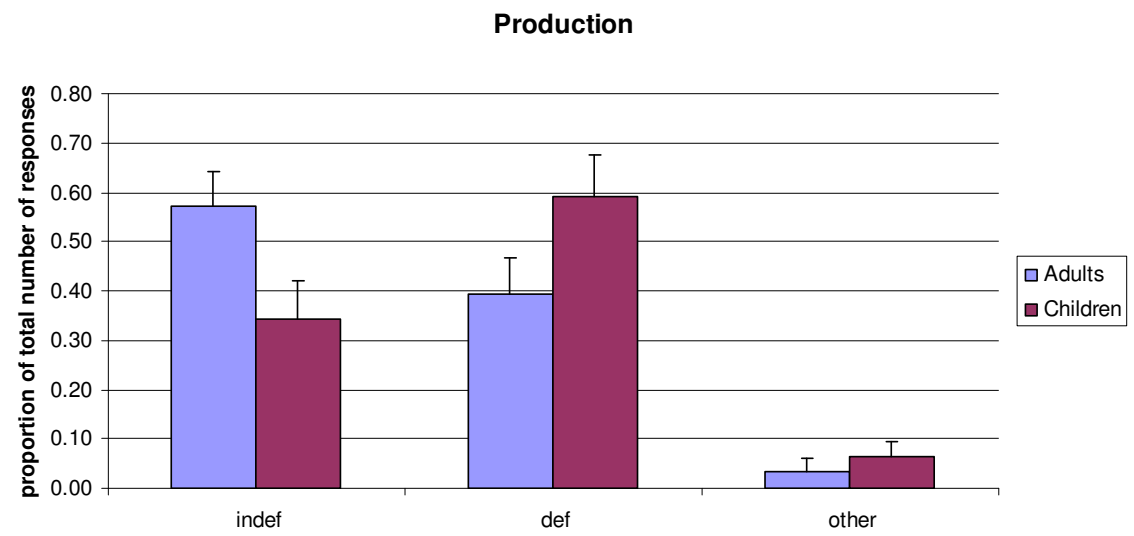

Figure 6. Production of indefinite versus definite subjects of transitive sentences by adults and children. The category 'other' includes unscorable utterances as well as subjects of intransitive sentences and passive sentences.

We were also interested in finding out what form participants would choose for the grammatical subjects in the sentences that were produced: an indefinite or a definite noun phrase. The category of indefinite noun 


\section{comprehension and production 17}

phrases includes noun phrases with an indefinite article (children: $57 \%$ of indefinite subjects, adults: $52 \%$ of indefinite subjects) as well as noun phrases with a bare numeral (children: $33 \%$, adults: $48 \%$ ) and plural forms without any article (children: $10 \%$, adults: $0 \%$ ). We calculated proportions of indefinite subjects, definite subjects and other productions for each participant. These proportions were arcsine transformed and entered into a Repeated Measures ANOVA with Type of Response (indefinite, definite, other), and Picture (1-3, 3-3, 3-1) as within-participants factors, and Group (children vs. adults) as between-participants factor. Figure 6 shows the mean proportions by participants averaged over pictures. The ANOVA showed an interaction between Group and Type of Response $(F(1,46)=3.7$; $\mathrm{p}=.050)$, which was due to children producing fewer indefinite $(\mathrm{p}<.05)$, but more definite subjects $(\mathrm{p}=.083)$ than adults; the difference in 'other' responses was not significant ( $\mathrm{p}>$.40). No other effects involving Group were significant ( $\mathrm{p}>$.19).

\subsection{Discussion}

In the production task, we aimed to elicit similar utterances as we tested in comprehension: utterances with an indefinite subject and a universally quantified object (IS-QO), and utterances with a universally quantified subject and an indefinite object (QS-IO). Our production results show that adults as well as children produced such utterances on the basis of the picture sequences. They produced utterances with an indefinite subject and a universally quantified object (IS-QO) for unique actors (1-3 picture sequences), and utterances with a universally quantified subject and an indefinite object (QS-IO) for non-unique undergoers (3-3 picture sequences) and unique undergoers (3-1 picture sequences). Importantly, they did not produce utterances with an indefinite subject and a universally quantified object (IS-QO) for non-unique actors (3-3 picture sequences). This is not particularly surprising for adults, as adults did not allow this form-meaning combination in comprehension either. So the adult pattern in production corresponds to their pattern in comprehension: Adults do not allow indefinite subjects to be interpreted non-specifically, and correspondingly do not produce indefinite subjects with a non-specific meaning. This suggests that specificity is not merely an interpretational phenomenon, as would follow from Philip's pragmatic treatment of quantifier scope in Dutch. Recall that, according to Philip's account, specificity is the result of an interpretive rule that requires listeners to 
select the strongest possible meaning (see Section 2.1). Consequently, there is no reason why we should find corresponding specificity effects in production.

Surprisingly, just like the adults, the children in our study did not produce IS-QO utterances for non-unique actors (3-3 picture sequences) either. This contrasts with the comprehension task, where children allowed indefinite subjects to be interpreted non-specifically. So children's pattern with non-specific indefinite subjects in comprehension is different from their pattern in production. In general, children hardly produced any IS-QO utterances. However, their avoidance of these constructions does not seem to indicate a lack of syntactic knowledge, as would be expected from a syntactic explanation of the quantifier scope restrictions in Dutch. The children did produce indefinite subjects in other transitive constructions, as can be seen from Figure 6. Also, they did not make any word order errors such as leaving the verb in final position or producing verb-subject order. In general, almost all utterances they produced were grammatical transitive sentences with SVO word order.

Children were not completely adult-like in their productions, however. They differed from adults in their production of specific indefinite subjects, and produced significantly fewer IS-QO utterances than adults in situations with a unique actor (1-3 picture sequences). They even produced a few QS-IO utterances, thus violating the anti-uniqueness presupposition of universal quantifiers according to which the domain of quantification must contain at least two elements. As children still make comprehension errors with this presupposition as late as age 6 (Yatsushiro, 2008), such violations can be expected to occur in production, too. These violations contribute to the general pattern that children, unlike adults, avoid producing specific indefinite subjects.

So why do children hardly produce any IS-QO utterances in situations with a unique actor, in contrast to adults? The semantic account predicts that both adults and children will avoid using an indefinite to refer to a specific referent, and use a definite instead. From this perspective, the crucial question is not why children avoid using indefinite subjects for specific referents, but rather why adults use an indefinite subject in these circumstances in as much as a third of the cases. To shed more light on this issue, we looked at the full set of utterances produced. Together with the two target forms IS-QO and QS-IO, transitive utterances with one or two definites (such as elke beer kietelt de schildpadden 'every bear tickles the turtles') or two indefinites (e.g., drie beren kietelen een schildpad 'three bears tickle a turtle') account for almost all of the production data. 


\section{comprehension and production 19}

Focusing on the production of definite and indefinite subjects, we find that, in general, children produced significantly more definite subjects and fewer indefinite subjects than adults, independently of the specificity of the referent. Additional analyses showed that children also produced slightly more definite objects than adults, but this difference was not significant. So perhaps the adults produced more IS-QO utterances than the children because in general they produced more indefinite subjects than the children.

At least two explanations are conceivable for our finding that adults produce indefinite subjects for specific referents. First, as the production task was preceded by the comprehension task, adults may have been primed more strongly than children (perhaps because of their larger working memory capacity) to produce similar forms as the ones that were presented in the comprehension task. As the comprehension task involved sentences with indefinite subjects, the adult participants may have been primed to use such forms in production, too. A second explanation for our finding is that givenness, or familiarity of the referent, may have had a different effect on children and adults. Adding a third constraint, M3 (*Def/-Fam: Avoid non-familiar definites, cf. Farkas \& de Swart, 2008), to the OT grammar under consideration may account for this selective influence of the (absence of) linguistic discourse. The OT tableaux below show the interaction among these constraints in the adult grammar (Figure 7) and the child grammar (Figure 8):

\begin{tabular}{|c|c|c|c|}
\hline $\begin{array}{l}\text { Input: } \\
+ \text { Spec, -Fam }\end{array}$ & $\begin{array}{l}\text { M1: } \\
* \text { S/-Spec; *O/+Spec }\end{array}$ & $\begin{array}{l}\text { M3: } \\
\text { *Def/-Fam }\end{array}$ & $\begin{array}{l}\text { M2: } \\
\text { *Indef/+Spec }\end{array}$ \\
\hline Indef & & & * \\
\hline Def & & $* !$ & \\
\hline
\end{tabular}

Figure 7. OT tableau of adult speakers' choice of form for a specific but nonfamiliar referent, with M1 outranking M2.

In the adult grammar, M1 is stronger than M2 (see Section 2.1). If the input to optimization is a referent that is specific but not familiar, a definite violates the M3 constraint on familiarity, whereas an indefinite violates the M2 constraint on specificity. If M3 is ranked higher than M2 in the adult grammar, the violation of M3 is fatal and hence an adult speaker will select an indefinite to express the input meaning. 


\begin{tabular}{|l||l|l|l|}
\hline $\begin{array}{l}\text { Input: } \\
\text { +Spec, -Fam }\end{array}$ & $\begin{array}{l}\text { M2: } \\
* \text { Indef/+Spec }\end{array}$ & $\begin{array}{l}\text { M3: } \\
* \text { Def/-Fam }\end{array}$ & $\begin{array}{l}\text { M1: } \\
* \text { S/-Spec;*O/+Spec }\end{array}$ \\
\hline \hline \multicolumn{1}{|c|}{ Indef } & $* !$ & & \\
\hline Def & & $*$ & \\
\hline
\end{tabular}

Figure 8. OT tableau of child speakers' choice of form for a specific but nonfamiliar referent, with M2 outranking M1.

A child entertaining a non-adult constraint ranking with $\mathrm{M} 2$ ranked highest (Figure 8) will, for the same input meaning, prefer a definite, as an indefinite would violate the strongest constraint M2.

According to this constraint-based explanation, the different patterns of adults and children may arise because the specificity constraint M2 and the familiarity constraint M3 are in conflict when the input meaning is specific but at the same time non-familiar. In all other situations, these constraints will yield the same output form for children and adults. These predictions about the interaction between specificity and familiarity are partly confirmed by our production data. Indeed, we found that children produced significantly more definite subjects than adults. However, they did so for subjects in general rather than for specific subjects only.

\section{Conclusion}

The question this study aimed to answer is why Dutch strongly prefers an indefinite subject in sentence-initial position to have wide scope with respect to a universally quantified direct object. We were interested in determining whether the preference for the wide scope reading in adult Dutch, and the lack of this preference in Dutch child language, is related to the preference to interpret an indefinite subject in sentence-inital position specifically. Therefore, we tested adults and 4- to 6-year-old children on their comprehension and production of universally quantified sentences in situations featuring specific versus non-specific referents. The results of our comprehension task confirm the findings of Philip (2005) that Dutch children, in contrast to Dutch adults, prefer a narrow scope interpretation according to which indefinite subjects in canonical position receive a nonspecific interpretation. The results of our parallel production task indicate that children's non-adult interpretations do not have a purely syntactic or pragmatic cause. Rather, children's acceptance of non-specific readings for 

comprehension and production 21

indefinite subjects in comprehension and their preference for definite subjects in production suggest that the scopal restrictions on indefinites in Dutch may be due to a non-adult ranking of constraints on specificity and familiarity.

\section{Notes}

1. Petra Hendriks gratefully acknowledges NWO (grant no. 277-70-005) for financial support. The authors thank Henk Leo Deuzeman, Douwe Schelvis, Jacolien van Rij and Charlotte Koster for their help in carrying out the experiment, and Tom Roeper, the Acquisition Lab Groningen, the audience of Linguistic Evidence 2010 and three anonymous reviewers for valuable comments.

2. Corrected degrees of freedom were used because of the violation of the equal variance assumption.

3. One of the reviewers wonders whether the low proportion of 'yes' responses for adults in the IS-QO 3-3 condition could have been due to the adult participants' expectancy to receive roughly equal numbers of 'yes' and 'no' items. However, if this were true, we would have seen comparable yes-no patterns across conditions. The fact that we did not, indicates that the adults made a linguistically based distinction between the four conditions.

4. In spontaneous speech, children as young as 3 seem to use referring forms in line with their givenness status (Gundel, Ntelitheos \& Kowalsky, 2007). In experimental tasks, however, children may be less sensitive to the givenness status of the referents, perhaps because givenness competes with other factors such as specificity. For example, van Hout, Harrigan and de Villiers (2010) found that English preschoolers use definite noun phrases to refer to new discourse entities and choose a given referent in more than half of the cases when hearing an indefinite noun phrase.

5. We only counted target utterances in the active voice, although some adult participants also produced passives. In coding the utterances, we ignored disambiguating expressions such as verschillende 'different', om de beurt 'in turn', allemaal 'all' and samen 'together', which were produced several times by children (in 4/204 utterances) and adults (in 13/240 utterances). 


\section{References}

Beghelli, F. \& T. Stowell

1997 Distributivity and negation: The syntax of each and every. In: A. Szabolcsi (Ed.), Ways of scope taking. Dordrecht: Kluwer, pp. 71107.

Bergsma-Klein, W.

1996 Specificity in child Dutch: An experimental study. MA Thesis, Utrecht University.

Dalrymple, M., M. Kanazawa, S. Mchombo \& S. Peters

1994 What do reciprocals mean? In: M. Harvey \& L. Santelmann (Eds), Proceedings of SALT IV. Ithaca: Cornell University, pp. 61-78.

de Hoop, H. \& I. Krämer

2005/6 Children's optimal interpretations of indefinite subjects and objects. Language Acquisition 13, 103-123.

Farkas, D. \& H. de Swart

2008 Article choice in plural generics. Lingua 117, 1657-1676.

Gundel, J. K., D. Ntelitheos \& M. Kowalsky

2007 Children's use of referring expressions: Some implications for Theory of Mind. In: D. Bittner \& N. Gagarina (Eds), ZAS Papers in Linguistics 48, 1-21.

Hendriks, P. \& J. Spenader

2005/6 When production precedes comprehension: An optimization approach to the acquisition of pronouns. Language Acquisition 13, 319-348.

Krämer, I.

1998 Children's interpretations of indefinite object noun phrases: Evidence from the scope of negation. In: R. van Bezooijen \& R. Kager (Eds), Linguistics in the Netherlands 1998, John Benjamins.

Philip, W.

2005 Pragmatic control of specificity and scope: Evidence from Dutch L1A. In: E. Maier, C. Bary \& J. Huitink (Eds), Proceedings of Sinn und Bedeutung 9, Nijmegen, pp. 271-285.

Prince, A. \& P. Smolensky

1993/2004 Optimality Theory: Constraint interaction in generative grammar. Technical Report, Rutgers University and University of Colorado at Boulder, 1993. Revised version published by Blackwell, 2004.

Prince, A. \& P. Smolensky

1997 Optimality: From neural networks to Universal Grammar. Science $275,1604-1610$. 
Restricting quantifier scope in Dutch: Evidence from child language comprehension and production 23

Stevens, J.

1992 Applied multivariate statistics for the social sciences. Second edition. Hillsdale, NJ: Lawrence Erlbaum Associates.

Tesar, B. \& P. Smolensky

1998 Learnability in Optimality Theory. Linguistic Inquiry 29, 229-268.

Unsworth, S.

2007 L1 and L2 acquisition between sentence and discourse: Comparing production and comprehension in child Dutch. Lingua 117, 19301958.

van Hout, A., K. Harrigan \& J. de Villiers

2010 Asymmetries in the acquisition of definite and indefinite noun phrases. Lingua 120, 1973-1990.

Yatsushiro, K.

2008 Quantifier acquisition: Presuppositions of "every". In: A. Grønn (Ed.), Proceedings of Sinn und Bedeutung 12, Oslo: ILOS, pp. 663676.

Wijnen, F. \& M. Verrips

1998 The acquisition of Dutch syntax. In: S. Gillis \& A. De Houwer (Eds), The acquisition of Dutch. Amsterdam: Benjamins 